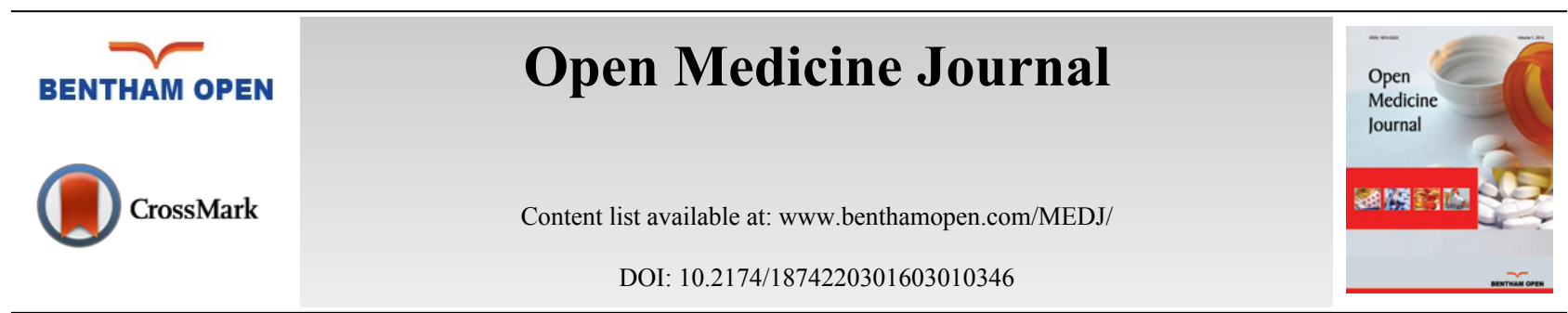

RESEARCH ARTICLE

\title{
Publishing in the Surgical Arena; Why, How and Where?
}

\author{
NT Mabvuure ${ }^{1}$, M Griffin ${ }^{2}$, S Hindocha ${ }^{3}$ and DJ Jordan ${ }^{3, *}$ \\ IGlasgow Royal Infirmary, Castle Street, Glasgow, UK \\ ${ }^{2}$ St. Georges Hospital, Tooting, London, UK \\ ${ }^{3}$ Department of Plastic Surgery, Whiston Hospital, Liverpool, UK
}

Received: July 07, 2015

Revised: September 17, 2016

Accepted: September 17, 2016

\begin{abstract}
Publication of peer-reviewed articles in journals remains the preferred means of communicating surgical and scientific advancements. Learning to publish is an important skill to gain for surgeons preparing for evidence based practice. Publications may also be used as evidence of academic pursuit and achievement during selection for surgical training posts. Bar a few courses, formal training in publishing is limited for surgeons outwith intercalated undergraduate and higher research degrees. This review explains the rational for publishing, as well as offering practical advice on various types of articles, selecting destination journal and maximising the visibility of published articles. We aim to guide surgeons through the process of publication. This review is aimed at a pan-subspecialty audience. However, examples relating to plastic surgery have been used to reflect the authors' collective experience.
\end{abstract}

Keywords: Article Writing, Publishing, Surgical Journals, Writing.

\section{INTRODUCTION}

Publication of peer-reviewed articles in journals remains the preferred means of communicating surgical and scientific advancements. This system enables the surgical community to scrutinise the presented work and ensures that the presenters are appropriately credited. The quantity, quality and impact of journal publications are widely used as surrogates for research activity and achievement. This has created a demand for journals. This demand for journals has created a thriving publishing business with numerous publishers appealing to niche markets. This complicated marketplace can be daunting to the novice surgeon intending to publish. Whilst the rewards of a good publication, at best, can lead to prestigious awards, the case of Dr. Wakefield offers a cautionary tale. This review intends to guide surgeons through the process of publication. The rational for publishing is explained and practical advice on choosing the appropriate types of article for a message, selecting destination journal and maximising the visibility of published articles is given. This discussion is relevant to a pan-subspecialty audience. However, examples relating to plastic surgery have been used to reflect the authors' collective experience.

\section{REASONS TO CONSIDER PUBLISHING}

Surgical research has previously been equated a comic opera for its lack of rigour [1]. However, since the paradigm shift towards strictly evidence-based practice, efforts have been made to improve the quality of surgical research. There are several approaches to ensuring the continued improvement of the quality of surgical research. One involves training residents not just in the conduct of high quality research, but also in communicating their findings through publication. Participation in research in itself enhances a surgeon's professional and academic development. However, research participation without measurable output may rouse suspicions. The publication of the results of research is ideal as the process of peer-review is intended to validate the scientific rigour of the presented work. Research participation without output (publication) may indeed be damaging to a surgeon's reputation as the assumption can be made that the research

\footnotetext{
* Address correspondence to this author at the Department of Plastic Surgery, Whiston Hospital, Liverpool, UK L35 5DR; Tel/Fax: + 44(0)1244366265; E-mail: jord_is@hotmail.com
} 
was of poor quality.

Publication may also provide evidence of intellectual ownership of an idea. Continued publication in a field may lead to 'thought leader' or expert status. This may be important should the surgeon wish to seek funding from external agencies for future research projects. Similarly, an institution's reputation and ranking in relation to rivals is partly dependent on its research output. Since an institution's reputation affects its ability to draw investment and forge commercial partnerships, it is unsurprising that the most prestigious institutions will seek to employ surgeons most likely to maintain, if not improve, its standing. Therefore, surgeons with high rates of high quality publications are more likely to be employed by prestigious institutions, which in turn are more likely to gain research funding. This positive "vicious" cycle enhances both the surgeon and institution's standing.

Although the advancement of surgical practice is the ultimate goal of publishing, not all publications achieve this. From a more pragmatic viewpoint, trainees intending to enter into highly competitive higher surgical training posts require publications as evidence of academic pursuit and achievement, among other achievements. In the United States (US), a 'prolific' publication record increases the chance of acceptance onto a residency programme [2]. In the UK, plastic surgery is one the most competitive specialties. On appointment to a training post, plastic surgery residents had a median of 5 (0-30) PubMed-indexed publications [3]. In 2003, 57\% of plastic surgery senior house officers had published articles [4]. Given these impressive records, applicants to such competitive programmes will require a strong publication record in order to be competitive.

Commencing the accrual of a publication record as medical students may be of advantage due to the reduction in time between graduation and selection for higher training [5]. In 2011, 14\% of surveyed UK medical students had submitted articles for publication [6]. A follow-up study found that students interested in plastic surgery had published more than their counterparts due to an awareness of future competitive pressures [7]. Although students' main motivations for publishing were non-altruistic (to progress careers [6, 7]), if appropriate quality checks are instituted at selection, this need not be seen as a negative. Macknin et al. found that $75 \%$ of residents who published during residency were significantly $(\mathrm{p}=0.02)$ more likely to continue publishing following completion of training [8]. Furthermore, Namdari et al. found that orthopaedic residents with a greater number of publications were more likely to pursue academic surgical careers [9]. Hence provided the appropriate monetary and supervisory support is available, trainees' non-altruistic motivations can be harnessed for the benefit of the specialty. Indeed, non-altruistic motivations for publishing are not unique to surgery and have been described in other specialties [10].

\section{WHAT TO PUBLISH}

There are several types of publications a surgeon may consider for presenting their work. They include original research articles, reviews, letters to the editor, and case reports. Original research articles in which a trainee has been involved in data collection and analysis may impart a fuller appreciation of the research process than other article types. Opportunities for engaging in original research may be intra or extracurricular. Intra-curricular research is usually performed during the pursuit of an intercalated undergraduate degree or higher research degree such as an MSc or PhD. A detailed review of such opportunities is beyond the scope of this review but can be found elsewhere [11 - 14]. Advantages of intra-curricular research include that it is usually conducted under the supervision of an academic and with recourse to university resources. Students may therefore have abundant support regarding publication in this setting. An example of intra-curricular research opportunities include the academic foundation programmes offered nationwide. However, most surgical research in the UK is extracurricular. With some initiative, it is possible to obtain a significant amount of original data on which to base publications as an extracurricular activity. Due to frequent relocation between training posts, it may be difficult to perform prospective studies such as randomised controlled trials. Hence, clinical research publications usually describe retrospective studies investigating outcomes from a Consultant's case records. Although providing a lower level of evidence than prospective studies, these studies can be performed relatively quickly and may provide practice-altering insights. Mabvuure et al. found that this was the most common type of article published by Consultant plastic surgeons [15]. Trainees intending to perform prospective studies may wish to join national research collaborates to increase both their sample sizes and the chance of publication. Several research-based collaborates, mostly trainee-led, have been established successfully in the UK. These collaborations have led to numerous high quality publications in high impact factor journals [16]. Local collaborations with other trainees may also help to ensure projects are completed. The authors, and others, have pursued such smallerscale collaborations which have included not just surgical trainees, but also medical students [17].

Other article types are also of value. Systematic reviews with or without meta-analysis usually provide the highest 
levels of evidence and can be performed from data collection to publication from home. Some surgical journals such International journal of Surgery and Interactive CardioVascular and Thoracic Surgery accept concise clinical reviews called best evidence topics (BETs). These BETs are a type of systematic review based on a specific clinical question usually when meta-analysis is not possible. They can usually be performed rapidly by a team of trainees. Case reports and series remain useful for documenting new diseases and providing reminders of important clinical points. Although these articles provide low levels of evidence, their brevity minimally disrupts trainees' clinical focus. Many surgical journals accept the most pertinent case reports and there are also now several journals dedicated to publishing surgical case reports and series. Letters and viewpoints, including responses to published articles, may advance new ideas as well as stimulate debate on topical issues. They may also demonstrate a surgeon's grasp of the literature surrounding the issues being discussed. In plastic surgery, the importance of cases and letters is demonstrated by them being the second and third most commonly published types of articles by UK consultants, respectively [15].

\section{WHERE TO PUBLISH}

There are several issues to consider before selecting a journal to submit work for publication. The choice of journal is crucial as it can affect a publication's visibility, reception and subsequently, citation. Publishing is a business. Vigilance is required to avoid unscrupulous publishers as demonstrated recently when 304 versions of a spoof paper with obvious flaws, including authorship by non-existent scientists, was submitted to several journals from various publishers [18]. The fact that 157 (52\%) versions had been accepted when the study was reported suggests that some journals' processes lack scientific rigour and probity. Such journals should be avoided as they may taint a surgeon's otherwise well-conducted and communicated work.

There are several detailed reviews advising on the selection destination journals $[10,19]$. In summary, they advise to consider a target journal before starting writing. This ensures the message is directed towards the appropriate audience and the article formatted to that journal's specifications early. It is important also to consider whether the journal accepts clinical or basic science articles. Depending on the generalizability of the article, a choice can then be made between generalist or specialist journals. For example, general plastic surgery journals such Plastic and Reconstructive Surgery and Journal of Plastic, Reconstructive \& Aesthetic Surgery accept articles covering all of that specialty's subspecialties, provided they are of sufficient cross-subspecialty interest. More specialised publications in aesthetic surgery and burns, for example, may be more appropriate, respectively, for journals such as Aesthetic Surgery Journal and Burns among similar titles. This is not unique to plastic surgery. It may be of value to a trainee to create a list of all relevant journals, detailing each journal's unique selling point.

Authors also need to decide between traditional (printed) and electronic journals, subscription access and open access [19]. Many traditional journals are now available in both print and electronically, ensuring as wide an audience as possible. Open access journals usually require a post-acceptance fee from authors without institutional cover. Unlike traditional journals, authors retain copyright and since the publications are available freely, they may be more accessible and therefore, cited [20]. However, this remains controversial with some studies showing no citation advantage [21]. Some suggest the positive effect on citations is only observed for higher quality research [22]. The distinction between open access and subscription journals has been blurred by many traditional journals now offering an open access option where authors pay fees and retain copyright. This may be desirable for authors keen on traditional journals but also attracted by the potentially unlimited availability of their work.

Authors are also advised to "balance the desire to publish in top-quality journals with the need for rapid publication [19]". This may be an important consideration for surgical trainees who may wish to complete publication before selection events. Rapid publication may be achieved by selecting journals with both rapid, rigorous peer review and online publication of articles in press. Other considerations include a journal's Pubmed-indexing status as only Pubmedindexed publications are recognised on surgical application forms. A journal's impact factor (the mean number of citations per article published in that journal in the preceding two years) may also be a consideration although it has several criticisms [23]. A more complete understanding of a journal's impact may include consideration of other bibliometric markers such as the Eigen factor, Article Influence score (AIS) and Source Normalised Impact per Paper (SNIP) among others. A discussions of the relative merits of these systems is beyond the scope of this article but is available elsewhere [23].

In practice, supervisors will usually advise on appropriate destination journals. However, there are other tools such as Elsevier's Journal Finder (http://www.elsevier.com/journal-authors/home), which may also help in deciding the most appropriate journal. 


\section{TRACKING AN ARTICLE'S IMPACT FOLLOWING PUBLICATION}

Publication in a high impact factor journal does not guarantee citation. Authors may need to work towards increasing the visibility of their work. This may involve presenting their work at scientific conferences as well as depositing articles in institutional repositories. Several online repositories such as Researchgate have emerged and may also increase a publication's visibility. However, authors should ensure they do not infringe on the journal's copyright when posting on these websites. There are now several publisher-owned and independent online tools to help authors track the performance of their publication. The number of citations can be tracked on several databases including Scopus, Web of Knowledge and Google Scholar among others. These resources often search different sources and may therefore have different results requiring a surgeon to search more than one of them [24]. Newer tools recognise that citations alone are not a complete measure of article impact. Online tools such as Altmetric.com (subscription) and ImpactStory.org (free) (Fig. 1) also collate other metrics such as social media sharing and the number of times an article has been saved by Mendeley readers. One paper found a statistic significance between higher altmetric scores being associated with higher citations [25], partially validating their use. Once a publication record has been gained, authors can then calculate their own impact using indices such as the Hirsch index, a measure of both productivity and impact [26].

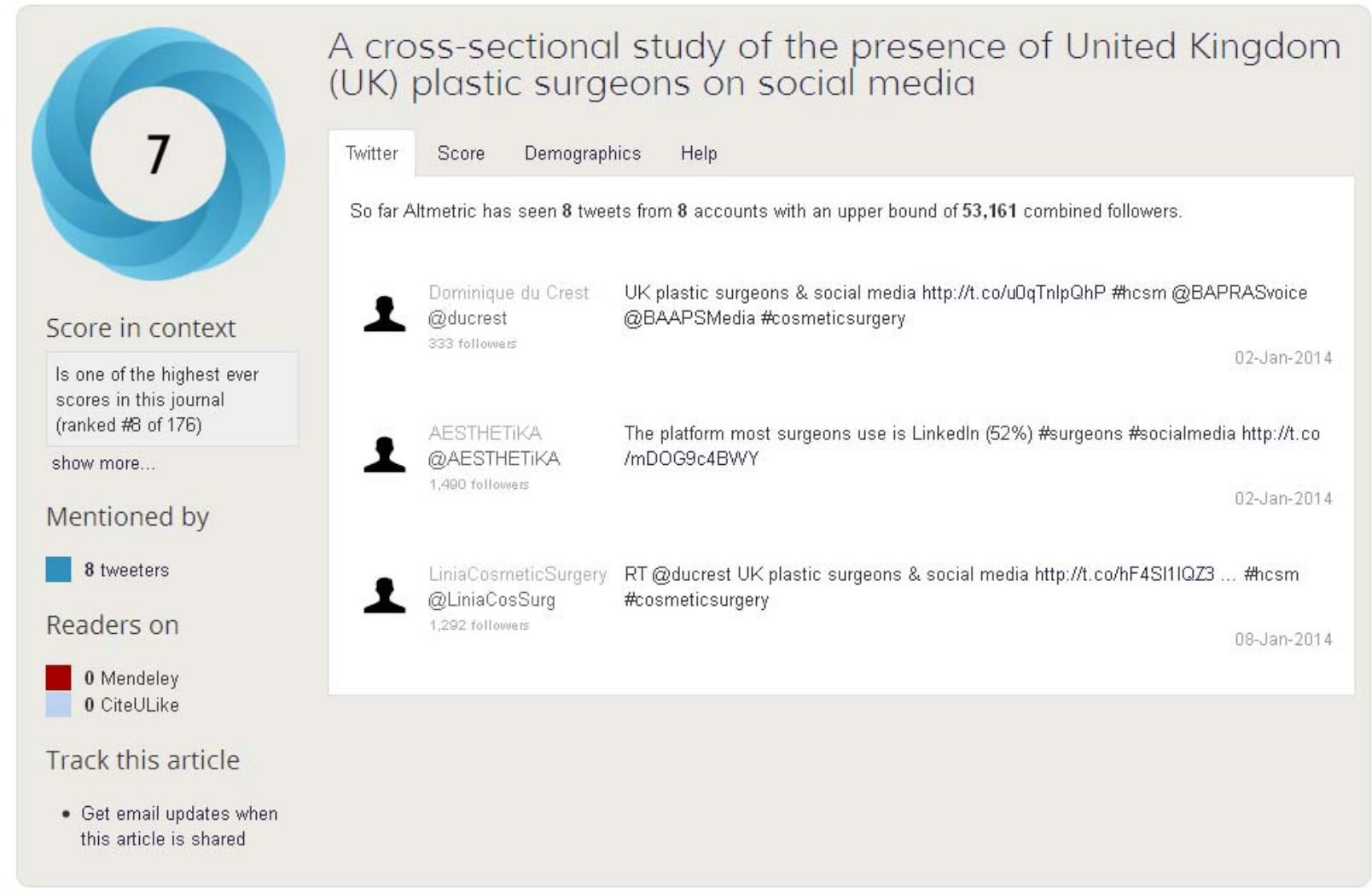

Fig. (1). Screenshot demonstrating the presentation of impact data on ImpactStory.org.

\section{CONCLUSION}

Publishing articles remains an important facet of surgical professional development. Surgeons are reminded that it is not just original research publications which carry scientific value. Other article types such as reviews, letters and case reports may at times provide more valuable additions to the literature. Destination journal selection is an important part of ensuring maximal exposure and impact for a publication. Consultation with colleagues as well as following the advice in this review may reduce the risk of disillusionment. Surgeons are also encouraged to actively increase the visibility of their research through various means such as conference presentation and social media sharing. The Writing Tips Series in the Journal of Clinical Epidemiology may also provide further useful information in addition to this review for surgeons intending to publish [19, 27 - 38]. 


\section{CONFLICT OF INTEREST}

The authors confirm that this article content has no conflict of interest.

\section{ACKNOWLEDGEMENTS}

Declared none.

\section{REFERENCES}

[1] Horton R. Surgical research or comic opera: questions, but few answers. Lancet 1996; 347(9007): $984-5$. [http://dx.doi.org/10.1016/S0140-6736(96)90137-3] [PMID: 8606606]

[2] Nagarkar P, Pulikkottil B, Patel A, Rohrich RJ. So you want to become a plastic surgeon? What you need to do and know to get into a plastic surgery residency. Plast Reconstr Surg 2013; 131(2): 419-22. [http://dx.doi.org/10.1097/PRS.0b013e31827c71bb] [PMID: 23142934]

[3] Jalali M, Davies PS, Jalali M, Tehrani H, Winterton RI. The UK plastic surgery trainee. J Plast Reconstr Aesthet Surg 2011 ; $64(12)$ : $1716-7$. [http://dx.doi.org/10.1016/j.bjps.2011.06.006] [PMID: 21704578]

[4] Whitaker IS, Eyre JR, Izadi D, Rhodes ND, Foo IT. Plastic surgery senior house officers in the UK and Ireland: academic background, publication rates and research plans. Br J Plast Surg 2004; 57(2): 139-42. [http://dx.doi.org/10.1016/j.bjps.2003.11.015] [PMID: 15037168]

[5] Mabvuure N. RE: Jalali et al. The UK plastic surgery trainee. J Plast Reconstr Aesthet Surg 2012; 65(4): e108-9. [http://dx.doi.org/10.1016/j.bjps.2011.11.042] [PMID: 22155083]

[6] Griffin MF, Hindocha S. Publication practices of medical students at British medical schools: experience, attitudes and barriers to publish. Med Teach 2011; 33(1): e1-8. [http://dx.doi.org/10.3109/0142159X.2011.530320] [PMID: 21182368]

[7] Mabvuure NT, Griffin MF, Hindocha S. The race to residency: publication practices of medical students interested in plastic surgery. Int J Surg 2014; 12(4): 367-8

[http://dx.doi.org/10.1016/j.ijsu.2014.01.020] [PMID: 24509401]

[8] Macknin JB, Brown A, Marcus RE. Does research participation make a difference in residency training? Clin Orthop Relat Res 2014; 472(1): $370-6$.

[http://dx.doi.org/10.1007/s11999-013-3233-y] [PMID: 23975249]

[9] Namdari S, Jani S, Baldwin K, Mehta S. What is the relationship between number of publications during orthopaedic residency and selection of an academic career? J Bone Joint Surg Am 2013; 95(7): e45. [http://dx.doi.org/10.2106/JBJS.J.00516] [PMID: 23553308]

[10] Thompson PJ. How to choose the right journal for your manuscript. Chest 2007; 132(3): $1073-6$ [http://dx.doi.org/10.1378/chest.07-1340] [PMID: 17873202]

[11] Taylor I. Opportunities for research in surgical training. Ann R Coll Surg Engl 1993; 75(2)(Suppl.): 31-2. [PMID: 8476196]

[12] Jain A, Nanchahal J. Research options for plastic surgical trainees. Br J Plast Surg 2002; 55(5): 427-9. [http://dx.doi.org/10.1054/bjps.2002.3875] [PMID: 12372373]

[13] Gordon C, Salmon M, Comm BR. Postgraduate degrees for rheumatology trainees: an options appraisal of MD, PhD and MSc degrees. On behalf of the BSR Research and Training Committee. Rheumatology (Oxford) 1999; 38(12): 1290-3. [http://dx.doi.org/10.1093/rheumatology/38.12.1290] [PMID: 10587563]

[14] Mabvuure NT. Twelve tips for introducing students to research and publishing: a medical students perspective. Med Teach 2012; 34(9): $705-9$.

[http://dx.doi.org/10.3109/0142159X.2012.684915] [PMID: 22905656]

[15] Mabvuure N, Griffin M, Hindocha S. Indexed publication practices of consultant plastic surgeons in the UK. Int J Surg 2012; 10(8): S71 [http://dx.doi.org/10.1016/j.ijsu.2012.06.374]

[16] Bhangu A, Kolias AG, Pinkney T, Hall NJ, Fitzgerald JE. Surgical research collaboratives in the UK. Lancet 2013; 382(9898): 1091-2. [http://dx.doi.org/10.1016/S0140-6736(13)62013-9] [PMID: 24075040]

[17] Mabvuure NT, Rodrigues JN, Hindocha S. Academic mentoring in surgery: applying the near-peer principles to the training hierarchy: including medical students. J Plast Reconstr Aesthet Surg 2014; 67(6): 879-81. [http://dx.doi.org/10.1016/j.bjps.2014.01.011] [PMID: 24508221]

[18] Bohannon J. Who's Afraid of Peer Review? Science 2013; 342(6154): 60-5. [http://dx.doi.org/10.1126/science.342.6154.60]

[19] Cals JW, Kotz D. Effective writing and publishing scientific papers, part X: choice of journal. J Clin Epidemiol 2014; 67(1): 3. [http://dx.doi.org/10.1016/j.jclinepi.2013.09.014] [PMID: 24183607]

[20] Eysenbach G. Citation advantage of open access articles. PLoS Biol 2006; 4(5): e157. 
[http://dx.doi.org/10.1371/journal.pbio.0040157] [PMID: 16683865]

[21] Davis PM. Open access, readership, citations: a randomized controlled trial of scientific journal publishing. FASEB J 2011; 25(7): 2129-34. [http://dx.doi.org/10.1096/fj.11-183988]

[22] Gargouri Y, Hajjem C, Larivière V, et al. Self-selected or mandated, open access increases citation impact for higher quality research. PLoS One 2010; 5(10): e13636. [http://dx.doi.org/10.1371/journal.pone.0013636] [PMID: 20976155]

[23] Oosthuizen JC, Fenton JE. Alternatives to the impact factor. Surgeon 2013; 12(5): 239-43. [PMID: 24246638]

[24] Bakkalbasi N, Bauer K, Glover J, Wang L. Three options for citation tracking: Google Scholar, Scopus and Web of Science. Biomed Digit Libr 2006; 3: 7 .

[http://dx.doi.org/10.1186/1742-5581-3-7] [PMID: 16805916]

[25] Thelwall M, Haustein S, Larivière V, Sugimoto CR. Do altmetrics work? Twitter and ten other social web services. PLoS One 2013; 8(5): e64841.

[http://dx.doi.org/10.1371/journal.pone.0064841] [PMID: 23724101]

[26] Hirsch JE. An index to quantify an individuals scientific research output. Proc Natl Acad Sci USA 2005; 102(46): 16569-72. [http://dx.doi.org/10.1073/pnas.0507655102] [PMID: 16275915]

[27] Kotz D, Cals JW. Effective writing and publishing scientific papers, part XII: responding to reviewers. J Clin Epidemiol 2014; 67(3): 243. [http://dx.doi.org/10.1016/j.jclinepi.2013.10.003] [PMID: 24411072]

[28] Kotz D, Cals JW. Effective writing and publishing scientific papers, part XI: submitting a paper. J Clin Epidemiol 2014; 67(2): 123. [http://dx.doi.org/10.1016/j.jclinepi.2013.10.004] [PMID: 24377385]

[29] Cals JW, Kotz D. Effective writing and publishing scientific papers, part IX: authorship. J Clin Epidemiol 2013; 66(12): 1319. [http://dx.doi.org/10.1016/j.jclinepi.2013.08.006] [PMID: 24369122]

[30] Cals JW, Kotz D. Effective writing and publishing scientific papers, part VIII: references. J Clin Epidemiol 2013; 66(11): 1198. [http://dx.doi.org/10.1016/j.jclinepi.2013.06.015] [PMID: 24079642]

[31] Cals JW, Kotz D. Effective writing and publishing scientific papers, part VI: discussion. J Clin Epidemiol 2013; 66(10): 1064. [discussion]. [http://dx.doi.org/10.1016/j.jclinepi.2013.04.017] [PMID: 23993311]

[32] Kotz D, Cals JW. Effective writing and publishing scientific papers, part VII: tables and figures. J Clin Epidemiol 2013; 66(11): 1197. [http://dx.doi.org/10.1016/j.jclinepi.2013.04.016] [PMID: 23958377]

[33] Kotz D, Cals JW. Effective writing and publishing scientific papers, part V: results. J Clin Epidemiol 2013; 66(9): 945. [http://dx.doi.org/10.1016/j.jclinepi.2013.04.003] [PMID: 23791158]

[34] Cals JW, Kotz D. Effective writing and publishing scientific papers, part III: introduction. J Clin Epidemiol 2013; 66(7): 702. [http://dx.doi.org/10.1016/j.jclinepi.2013.01.004] [PMID: 23497856]

[35] Kotz D, Cals JW. Effective writing and publishing scientific paperspart I: how to get started. J Clin Epidemiol 2013; 66(4): 397. [http://dx.doi.org/10.1016/j.jclinepi.2013.01.002] [PMID: 23452726]

[36] Kotz D, Cals JW, Tugwell P, Knottnerus JA. Introducing a new series on effective writing and publishing of scientific papers. J Clin Epidemiol 2013; 66(4): 359-60.

[http://dx.doi.org/10.1016/j.jclinepi.2013.01.001] [PMID: 23452725]

[37] Kotz D, Cals JW. Effective writing and publishing scientific papers, part IV: methods. J Clin Epidemiol 2013; 66(8): 817. [http://dx.doi.org/10.1016/j.jclinepi.2013.01.003] [PMID: 23434330]

[38] Cals JW, Kotz D. Effective writing and publishing scientific papers, part II: title and abstract. J Clin Epidemiol 2013; 66(6): 585. [http://dx.doi.org/10.1016/j.jclinepi.2013.01.005] [PMID: 23434329]

(C) Mabvuure et al.; Licensee Bentham Open

This is an open access article licensed under the terms of the Creative Commons Attribution-Non-Commercial 4.0 International Public License (CC BY-NC 4.0) (https://creativecommons.org/licenses/by-nc/4.0/legalcode), which permits unrestricted, non-commercial use, distribution and reproduction in any medium, provided the work is properly cited. 